\title{
The Distribution of Isoprenoid Quinones in Streptococci of Serological Groups D and N
}

\author{
By M. D. COLLINS AND DOROTHY JONES \\ Department of Microbiology, School of Medicine and School of Biological Sciences, \\ University of Leicester, Leicester LE1 7RH
}

(Received 24 January 1979)

\begin{abstract}
The isoprenoid quinone contents of streptococci of serological groups $\mathrm{D}$ and $\mathrm{N}$ were investigated. Streptococcus faecalis, $S$. faecalis subsp. liquefaciens and $S$. faecalis subsp. zymogenes strains contained demethylmenaquinones with nine isoprene units as their major isoprenologues. Menaquinones with eight isoprene units predominated in $S$. faecium subsp. casseliflavus and $S$. faecium subsp. mobilis whereas menaquinones with nine isoprene units constituted the major components in strains of $S$. cremoris, $S$. cremoris subsp. alactosus, $S$. lactis and $S$. lactis subsp. diacetylactis. Strains of $S$. avium, $S$. bovis, $S$. durans, $S$. equinus, $S$. faecium, $S$. raffinolactis and $S$. suis contained neither menaquinones nor ubiquinones. The isoprenoid quinone data correlate well with other kinds of data on these organisms and are of value in the classification of these bacteria.
\end{abstract}

\section{INTRODUCTION}

Bacteria of the genus Streptococcus are conventionally considered to be facultative anaerobes with a preference for anaerobic conditions. They grow aerobically but are unable to synthesize porphyrins and hence cytochromes. However, cytochromes have been demonstrated in strains of Streptococcus faecalis grown in media containing haem compounds (Whittenbury, 1964, 1978; Bryan-Jones \& Whittenbury, 1969; Sijpesteijn, 1970; Ritchey \& Seeley, 1974, 1976; Pritchard \& Wimpenny, 1978). A systematic survey of the distribution of 'cytochrome-like respiration' amongst representatives of the genus Streptococcus (Ritchey \& Seeley, 1976) indicated that this ability was restricted to $S$. faecalis and its subspecies $S$. faecalis subsp. liquefaciens and $S$. faecalis subsp. zymogenes (serological group D, Lancefield, 1933) and to a few strains designated Streptococcus lactis and S. lactis subsp. diacetylactis (serological group N, Lancefield; Shattock \& Mattick, 1943).

Menaquinones [2-methyl-3-(prenyl) $)_{n}$-1,4-naphthoquinones; I] and ubiquinones [2,3dimethoxy-5-methyl-6-(prenyl) $)_{n}$-1,4-benzoquinones; II] are constituents of bacterial plasma membranes (Pennock, 1966) and play an important role in electron transport and possibly oxidative phosphorylation (Brodie \& Watanabe, 1966; Redfearn, 1966; Dunphy \& Brodie, 1971). Baum \& Dolin (1963) isolated a novel naphthoquinone from $S$. faecalis (strain 10C1) which had ultraviolet absorption characteristics distinct from the strict menaquinone family (I). This naphthoquinone was later shown to be a modified menaquinone in which the methyl group at C-2 had been replaced by a hydrogen atom (referred to as demethylmenaquinones: Baum \& Dolin, 1965; Dolin \& Baum, 1965). Streptococcus faecalis strain 10C1 has since been shown to be capable of oxidative phosphorylation (Gallin \& Vandemark, 1964) and of forming a functional cytochrome system (Smalley et al., 1968; Ritchey \& Seeley, 1976). To our knowledge, however, no data are available on the presence of isoprenoid quinones in any other strain of $S$. faecalis or in any other streptococci of serological groups $\mathrm{D}$ and $\mathrm{N}$. 
I<smiles>CCCCCCCCCCC</smiles>

Menaquinone- $n$ $(\mathrm{MK}-n)$<smiles>CCCCCCCCCCC</smiles>

Ubiquinone- $n$ (Q-n)

Isoprenoid quinone structural types have been shown to be of taxonomic value in many groups of bacteria (Yamada et al., 1976a, b; Collins et al., 1977, 1979a, b; Minnikin et al., $1978 a, b)$. In view of the unsatisfactory taxonomic state of streptococci of serological groups D and N (for review, see Jones, 1978), we have investigated the type and distribution of isoprenoid quinones amongst representatives of these two serological groups together with some other streptococci and representatives of the genera Aerococcus, Gemella, Leuconostoc and Pediococcus.

\section{METHODS}

Strains and cultivation. Details of the test strains are shown in Tables 1 to 3. The aerococci, pediococci, leuconostocs and streptococci were grown in shake flasks in nutrient broth no. 2 (Oxoid) supplemented with glucose $\left(2 \mathrm{mg} \mathrm{ml}^{-1}\right)$ and haemin $\left(7.5 \mu \mathrm{g} \mathrm{ml}^{-1}\right)$ for $2 \mathrm{~d}$ at $30^{\circ} \mathrm{C}$. The single strain of Gemella haemolysans was grown in shake culture for $3 \mathrm{~d}$ at $30^{\circ} \mathrm{C}$ in nutrient broth no. 2 supplemented with glucose $\left(2 \mathrm{mg} \mathrm{ml}^{-1}\right)$, haemin $\left(7 \cdot 5 \mu \mathrm{g} \mathrm{ml}^{-1}\right)$ and horse serum $(1 \%, \mathrm{v} / \mathrm{v})$. Cultures were checked for purity at maximum growth, collected by centrifugation, washed with distilled water and freeze-dried.

Extraction and purification of isoprenoid quinones. Dried organisms (250 $\mathrm{mg})$ were examined using the procedure described by Collins et al. (1977).

Analysis of isoprenoid quinones. Purified isoprenoid quinones were further examined by reverse phase partition chromatography using Whatman $\mathrm{KC}_{18} \mathrm{~F}$ reverse phase thin-layer plates and a polar developing mixture of acetone/water (97:3, v/v) (Collins et al., 1979 b). Ultraviolet spectra of the quinones were recorded in iso-octane on a Perkin-Elmer (model $137 \mathrm{UV}$ ) spectrophotometer. Mass spectra of the isoprenoid quinones were recorded on an AEI MS9 instrument using a direct insertion probe, an ionizing voltage of $70 \mathrm{eV}$ and a temperature range of 200 to $230^{\circ} \mathrm{C}$. (Detailed mass spectra may be obtained from the authors on request.)

\section{RESULTS}

Components that co-chromatographed with vitamin $\mathrm{K}$ were the only isoprenoid quinones detected in the extracts of strains of S. cremoris, S. cremoris subsp. alactosus, $S$. faecalis, $S$. faecalis subsp. liquefaciens, $S$. faecalis subsp. zymogenes, $S$. faecium subsp. casseliflavus, $S$. faecium subsp. mobilis, $S$. lactis and $S$. lactis subsp. diacetylactis. Neither menaquinones (vitamin $\mathrm{K}$ ) nor ubiquinones (coenzyme Q) were detected in the lipid extracts of the remaining 36 strains of streptococci or in strains of the genera Aerococcus, Gemella, Leuconostoc and Pediococcus (Table 1).

The purified isoprenoid quinones from strains of $S$. cremoris, S. cremoris subsp. alactosus, S. faecium subsp. casseliflavus, S. faecium subsp. mobilis, S. lactis and S. lactis subsp. diacetylactis had ultraviolet absorption maxima at 242, 248, 260, 270 and $326 \mathrm{~nm}$. This is in accord with published data for menaquinones (Dunphy \& Brodie, 1971). However, the isoprenoid quinones from strains of $S$. faecalis, $S$. faecalis subsp. liquefaciens and $S$. faecalis subsp. zymogenes had absorption maxima at 243,248,254, 263 and $326 \mathrm{~nm}$ indicating the presence of demethylmenaquinones (Dunphy \& Brodie, 1971). On mass spectrometry, the menaquinones from strains of $S$. cremoris, $S$. cremoris subsp. alactosus, $S$. faecium subsp. casseliflavus, $S$. faecium subsp. mobilis, $S$. lactis and $S$. lactis subsp. diacetylactis produced base peaks at $m / e 225$, derived from the naphthoquinone nucleus, and intense peaks at $m / e$ 187. The mass spectra of the demethylmenaquinones from $S$. faecalis strains produced intense peaks at $m / e 211$, thereby confirming that the methyl group at C-2 has been replaced 
Table 1. Taxa lacking both menaquinones and ubiquinones

Strain designation/source $\|$

Aerococcus catalasicus NCIB 9642

A. catalasicus NCIB 9643

Aerococcus viridans NCIB 9206

Gemella haemolysans NCTC 10244

Leuconostoc dextranicum NCIB 2706

L. mesenteroides NCIB 3351

Pediococcus acidilactici NCIB $7881 \dagger$

$P$. parvulus NCDO 1250

$P$. pentosaceous NCIB $8106 \dagger$

Streptococcus agalactiae (group B)§ NCDO 1352

S. avium (group Q); R. H. Deibel, SS1 $\uparrow$

S. avium (group Q); R. H. Deibel, CCP1

$S$. avium (group Q); R. H. Deibel, Strep A

* $S$. bovis ATCC $9809+$

S. bovis NCDO 599

S. bovis; E. M. Barnes, TM/C/33

* $S$. durans NCDO 596†

S. durans NCTC 8307

$S$. durans; E. M. Barnes, 98D

S. dysgalactiae (group C) NCDO 1356

S. equi (group C) NCTC 9682

$S$. equinus NCDO $1090 \dagger$

$S$. equinus NCDO 1091

S. equisimilis (group C) NCTC 5371

* Type strain.

† Taxa which react with group D antiserum (see Jones, 1978; Whittenbury, 1978).

¥ Taxa which react with group $\mathrm{N}$ antiserum (see Jones, 1978).

$\S$ Serological group.

If Sources, other than recognized culture collections, were: E. M. Barnes, Food Research Institute, Colney Lane, Norwich; R. H. Deibel, Department of Bacteriology, University of Wisconsin, Wisconsin, U.S.A.; R. K. A. Feltham, Department of Microbiology, University of Leicester, Leicester.

by a hydrogen atom. The mass spectra of both the menaquinones and demethylmenaquinones in the high mass region contained strong peaks corresponding to molecular ions $\left(\mathrm{M}^{+}\right)$. Details of the mass spectral analyses of the isoprenoid quinones are shown in Tables 2 and 3.

Streptococcus faecium subsp. casseliflavus and $S$. faecium subsp. mobilis strains contained comparable amounts of menaquinones with seven and eight isoprene units (abbreviated as MK-7 and MK-8, respectively). Menaquinones with nine isoprene units predominated in strains of $S$. cremoris, $S$. cremoris subsp. alactosus, $S$. lactis and $S$. lactis subsp. diacetylactis (Table 2). In contrast, strains of $S$. faecalis, $S$. faecalis subsp. liquefaciens and $S$. faecalis subsp. zymogenes contained demethylmenaquinones with nine isoprene units (abbreviated DMK-9) as the major isoprenologue, with smaller quantities of DMK-6, DMK-7 and DMK-8 (Table 3). The proportions of the major isoprenologues found by mass spectrometry were confirmed by the results of reverse phase partition chromatography.

\section{DISCUSSION}

The recovery of demethylmenaquinones with nine isoprene units from strains of $S$. faecalis confirms the findings of Baum \& Dolin $(1963,1965)$ and is in accord with the presence of a cytochrome-like respiration system. Identical demethylmenaquinone patterns were also observed in strains of $S$. faecalis subsp. liquefaciens (non-haemolytic, gelatin liquefied) and $S$. faecalis subsp. zymogenes ( $\beta$-haemolytic, gelatin may or may not be liquefied) (Deibel \& Seeley, 1974). Deibel (1964) and Jones et al. (1972) have questioned the validity of these 
Table 2. Peaks corresponding to molecular ions in the mass spectra of menaquinones isolated from Streptococcus species

The main component in each series is denoted by +++ , any component greater than $50 \%$ of the main peak by ++ and all other significant components by + .

Menaquinone isoprenologue

$m / e$

S. faecium subsp. casseliflavus ATCC $25788 \dagger$

S. faecium subsp. casseliflavus ATCC 25789

$S$. faecium subsp. mobilis ATCC 14436†

S. faecium subsp. mobilis NCIB 9645

S. cremoris NCDO 495‡

* S. cremoris NCDO 607

S. cremoris NCDO 762

S. cremoris NCDO 2006

S. cremoris subsp. alactosus NCDO $1032 \ddagger$

* S. lactis NCDO 604‡.

S. lactis NCIB 10769

S. lactis subsp. diacetylactis NCDO $176 \ddagger$

S. lactis subsp. diacetylactis NCDO 1007

S. lactis subsp. diacetylactis NCDO 1008

S. lactis subsp. diacetylactis NCIB 8763

$S$. lactis subsp. diacetylactis NCIB 10493

$\begin{array}{cc}\text { MK-6 } & \text { MK-7 } \\ 580 & 648 \\ + & ++\S \\ + & ++\S \\ + & ++\S \\ + & ++\S \\ + & + \\ + & + \\ + & + \\ + & + \\ + & + \\ + & + \\ + & + \\ + & + \\ + & + \\ + & + \\ + & + \\ + & +\end{array}$

MK-8 716

MK-9 784

$++$

$++$

$+++$

$++$

$+$

$+$

$+$

$+$

$+$

$+$

+
+

$+$

+
+

+
+

+
+
$-$

$-$

$-$

$-$

$++$

$+++$

$++$

$++$

$++$

$++$

$+++$

$+++$

$+++$

$++$

$+++$

$+++$

Strains of $S$. cremoris, $S$. cremoris subsp. alactosus, $S$. lactis and $S$. lactis subsp. diacetylactis also contained traces of MK-10 $(m / e$ 852).

* Type strain.

$\dagger$ Taxa which react with group D antiserum (see Jones, 1978).

$\$$ Taxa which react with group $\mathrm{N}$ antiserum (see Jones, 1978).

$\S$ Intensity very similar to main peak.

Table 3. Peaks corresponding to molecular ions in the mass spectra of demethylmenaquinones isolated from Streptococcus faecalis

The main component in each series is denoted by +++ , any component greater than $50 \%$ of the main peak by ++ and all other significant components by + .

Demethylmenaquinone isoprenologue $m / e$

S. faecalis NCIB $6782 \dagger$

S. faecalis NCTC 8729

S. faecalis subsp. liquefaciens NCTC $8175 \dagger$

$S$. faecalis subsp. zymogenes NCTC $8176 \dagger$

$S$. faecalis subsp. zymogenes NCTC 5957

$\begin{array}{cc}\text { DMK-6 } & \text { DMK-7 } \\ 566 & 634 \\ + & + \\ + & + \\ + & + \\ + & + \\ + & +\end{array}$

$\underset{702}{\text { DMK-8 }}$

DMK-9

770

$++$

$++$

$++$

$++$

$++$
$+++$

$+++$

$++$

$+++$

$+++$

Mass spectroscopy and reverse phase partition chromatography also revealed trace amounts of DMK-10 in the extracts of all the $S$. faecalis strains.

$\dagger$ Taxa which react with group D antiserum (see Jones, 1978).

subspecies and consider all should be included in one species, S. faecalis. The present quinone findings add weight to this view. Pette (1955) isolated some atypical $S$. faecalis strains from Gouda cheese and proposed the new variety $S$. faecalis var. malodoratus. However, the numerical taxonomic study of Jones et al. (1972) indicated no close relationship between these strains and $S$. faecalis. The presence of demethylmenaquinones in strains of $S$. faecalis, S. faecalis subsp. liquefaciens and $S$. faecalis subsp. zymogenes and their absence from $S$. faecalis var. malodoratus strains is in accord with the results of the numerical study of Jones et al. (1972) and suggests that the latter should be excluded from the species S. faecalis.

Streptococcus faecium (Orla-Jensen) is now recognized as a well-defined taxon distinct from $S$. faecalis (see Deibel \& Seeley, 1974). The absence of demethylmenaquinones from 
strains of the former and their presence in strains of the latter species reinforces this distinction. It is also generally agreed that strains previously called $S$. durans (Sherman \& Wing, 1937) should be classified as $S$. faecium (Deibel, 1964; Jones et al., 1972). The lack of isoprenoid quinones in strains of both these taxa does not contradict this view (Table 1).

Strains of S. faecium subsp. casseliflavus (Mundt \& Graham, 1968) and S. faecium subsp. mobilis (Langston et al., 1960) differ quite markedly in some respects from strains of S. faecium (Lund, 1967; Mundt \& Graham, 1968; Roop et al., 1974). The detection of major amounts of MK-7 and MK-8 in strains of the first two taxa but not in those of $S$. faecium underlines this distinction and suggests, along with other evidence (see Jones, 1978), that $S$. faecium subsp. casseliflavus and $S$. faecium subsp. mobilis are probably closely related to each other but are sufficiently distinct from $S$. faecium and $S$. faecalis to be excluded from both these species.

The recovery of menaquinones from strains of $S$. lactis and $S$. lactis subsp. diacetylactis is in accord with the reports of cytochrome-mediated electron transport in strains of these taxa when grown in the presence of preformed haem (Sijpesteijn, 1970; Ritchey \& Seeley, 1976). Streptococcus lactis is now a well described species (see Deibel \& Seeley, 1974; Jones, 1978) although the taxonomic status of S. lactis subsp. diacetylactis (Matuszewski et al., 1936) remains equivocal. Streptococcus lactis subsp. diacetylactis has the same characteristics as $S$. lactis except that the former metabolizes citrate in the presence of fermentable carbohydrate to form acetoin, diacetyl and $\mathrm{CO}_{2}$. The identical menaquinone profiles of strains of both $S$. lactis and $S$. lactis subsp. diacetylactis underlines the close relationship between these taxa and strengthens the case for reducing $S$. lactis subsp. diacetylactis to $S$. lactis (see Jones, 1978).

Cytochrome-mediated electron transport in S. cremoris strains has not to our knowledge been described to date. However, the detection of menaquinones in strains of both $S$. cremoris and $S$. cremoris subsp. alactosus suggests such an investigation may prove rewarding. Streptococcus cremoris and S. lactis share many biochemical properties (see Jones, 1978) and preliminary DNA-DNA homology studies (Garvie, 1978) indicate a similarity between these species. It is probable that $S$. cremoris is a variety of $S$. lactis more adapted to a dairy environment (Jones, 1978). The closely related menaquinone profiles of strains of both taxa lend weight to this view.

On the basis of lactate dehydrogenase properties, $\% \mathrm{G}+\mathrm{C}$ determinations and DNADNA homology studies, Garvie (1978) concluded that those streptococci for which she proposed the name $S$. raffinolactis are sufficiently distinct from $S$. cremoris and $S$. lactis to warrant separate species status. The apparent absence of menaquinones from strains of $S$. raffinolactis and their presence in the other streptococci of serological group $\mathrm{N}$ examined is in accord with this view.

The lack of both menaquinones and ubiquinones in the remaining streptococci examined, i.e. S. agalactiae, S. avium, S. bovis, S. dysgalactiae, S. equi, S. equinus, S. equisimilis, $S$. milleri, $S$. mutans subsp. sobrinus, $S$. pneumoniae, $S$. pyogenes, $S$. salivarius, $S$. sanguis, $S$. suis and $S$. uberis, is in keeping with the absence of a functional cytochrome-like respiratory system (Ritchey \& Seeley, 1976; Whittenbury, 1978).

Members of the genera Aerococcus and Pediococcus possess many biochemical properties in common with the genus Streptococcus. Indeed, the major reason for excluding aerococci and pediococci from the genus Streptococcus is the mode of cell division (see Jones, 1978; Whittenbury, 1978). The absence of isoprenoid quinones from aerococci and pediococci reinforces their close relationship to the majority of streptococci as represented by the examples examined here.

Gemella haemolysans was initially classified in the Gram-negative genus Neisseria, but subsequent work indicated this species had a Gram-positive wall structure and was probably more closely related to the 'lactic acid' bacteria (Reyn, 1970, 1974; Reyn et al., 1970; Wilkinson \& Jones, 1977). In the 8th edition of Bergey's Manual of Determinative Bacterio- 
$\log y$ (Buchanan \& Gibbons, 1974), Gemella haemolysans is classified in the family Streptococcaceae (Deibel \& Seeley, 1974; Reyn, 1974). The lack of detectable isoprenoid quinones in strains of Gemella haemolysans does not contradict its classification in the Streptococcaceae and clearly distinguishes it from members of the genus Neisseria which contain ubiquinones (coenzyme Q) as their sole isoprenoid quinones (Bishop et al., 1962; Beebe, 1974).

The presence of different types of menaquinones in strains of some species known to react with Lancefield group $\mathrm{D}$ and group $\mathrm{N}$ antisera, and the apparent absence of menaquinones from others, further emphasizes the physiological heterogeneity of the taxa in these two serological groups. In addition, the data underline the strictures of Jones (1978) concerning the undue weight given in the past to serological grouping in streptococcal classification.

We are grateful to R. H. Deibel, E. M. Barnes and R. K. A. Feltham for generously supplying strains (see Table 1), and to the Department of Organic Chemistry, University of Leicester, for providing mass spectrometry facilities. We thank the Medical Research Council for support (grant G977/613/S).

\section{REFERENCES}

BAum, R. H. \& Dolin, M. I. (1963). Isolation of a new naphthoquinone from Streptococcus faecalis 10C1. Journal of Biological Chemistry 238, PC4109-4111.

BAum, R. H. \& Dolin, M. I. (1965). Isolation of 2-solanesyl-1,4-naphthoquinone from Streptococcus faecalis, 10C1. Journal of Biological Chemistry 240, 3425-3433.

BEEBE, J. L. (1974). Lipid composition of Neisseria catarrhalis. Abstracts of the Annual Meeting of the American Society for Microbiology, p. 45.

Bishop, D. H. L., Pandya, K. P. \& King, H. K. (1962). Ubiquinone and vitamin $K$ in bacteria. Biochemical Journal 83, 606-614.

Brodie, A. F. \& Watanabe, T. (1966). Mode of action of vitamin $\mathrm{K}$ in micro-organisms. Vitamins and Hormones 24, 447-463.

BRyAN-Jones, D. G. \& WhitTenbury, R. (1969). Haematin-dependent oxidative phosphorylation in Streptococcus faecalis. Journal of General Microbiology 58, 247-260.

Buchanan, R. E. \& Gibbons, N. E. (editors) (1974). Bergey's Manual of Determinative Bacteriology, 8th edn. Baltimore: Williams \& Wilkins.

Collins, M. D., Pirouz, T., Goodfellow, M. \& Minnikin, D. E. (1977). Distribution of menaquinones in actinomycetes and corynebacteria. Journal of General Microbiology 100, 221-230.

Collins, M. D., Goodfellow, M. \& Minnikin, D. E. $(1979 a)$. Isoprenoid quinones in the classification of coryneform and related bacteria. Journal of General Microbiology 110, 127-136.

Collins, M. D., Jones, D., Goodfellow, M. \& MinNiKIN, D. E. (1979b). Isoprenoid quinone composition as a guide to the classification of Listeria, Brochothrix, Erysipelothrix and Caryophanon. Journal of General Microbiology 111, 453-457.

DeIBEL, R. H. (1964). The group D streptococci. Bacteriological Reviews 28, 330-366.

Deibel, R. H. \& SeEley, H. W. (1974). Streptococcaceae fam. nov. In Bergey's Manual of Determinative Bacteriology, 8th edn, pp. 490-509.
Edited by R. E. Buchanan \& N. E. Gibbons. Baltimore: Williams \& Wilkins.

Dolin, M. I. \& BAUM, R. H. (1965). Evidence of thioether formation between 2-solanesyl-1,4naphthoquinone and 2-mercaptoethanol. Biochemical and Biophysical Research Communications 18, 202-205.

DunPHy, P. J. \& Brodie, A. F. (1971). The structure and function of quinones in respiratory metabolism. Methods in Enzymology 18, 407-461.

Gallin, J. I. \& VANDEMARK, P. J. (1964). Evidence for oxidative phosphorylation in Streptococcus faecalis. Biochemical and Biophysical Research Communications 17, 630-635.

GARVIE, E. I. (1978). Streptococcus raffinolactis (Orla-Jensen \& Hansen); a group N streptococcus found in raw milk. International Journal of Systematic Bacteriology 28, 190-193.

JONES, D. (1978). Composition and differentiation of the genus Streptococcus. In Streptococci, pp. 1-49. Edited by F. A. Skinner \& L. B. Quesnel. London: Academic Press.

Jones, D., Sackin, M. J. \& SNeath, P. H. A. (1972). A numerical taxonomic study of streptococci of serological group D. Journal of General Microbiology 72, 439-450.

LANCEFIELD, R. C. (1933). A serological differentiation of human and other groups of hemolytic streptococci. Journal of Experimental Medicine 57, 571-595.

Langston, C. W., Guttierrez, J. \& Bouma, C. (1960). Motile enterococci (Streptococcus faecium var. mobilis var. $\mathrm{N}$ ) isolated from grass silage. Journal of Bacteriology 80, 714-718.

LUND, B. M. (1967). A study of some motile group D streptococci. Journal of General Microbiology 49, 67-80.

Matuszewski, T., Pujanowski, E. \& Supinska, J. (1936). Streptococcus diacetilactis n.sp. and its application to butter making. Roczników Nauk Rolniczych I Lésnych (Polish Agricultural and Forestry Annual) 36, 1-28. 
Minnikin, D. E., Collins, M. D. \& Goodfellow, M. $(1978 a)$. Menaquinone patterns in the classification of nocardioform and related bacteria. Zentralblatt für Bakteriologie, Parasitenkunde, Infektionskrankheiten und Hygiene (Abteilung I), Supplement 6, 85-90.

Minnikin, D. E., Goodfellow, M. \& Collins, M. D. (1978b). Lipid composition in the classification and identification of coryneform and related taxa. In Coryneform Bacteria, pp. 85-160. Edited by I. J. Bousfield \& A. G. Callely. London: Academic Press.

Mundt, J. O. \& Graham, W. F. (1968). Streptococcus faecium var. casseliflavus nov.var. Journcl of Bacteriology 95, 2005-2009.

PenNock, J. F. (1966). Occurrence of vitamins K and related quinones. Vitamins and Hormones 24, 307-329.

Petre, J. W. (1955). De vorming van zwatelwaterstof in Goudse Kaas, veroorzaakt door melkzuurbacterien. Netherlands Milk and Dairy Journal 10, 291-302.

Pritchard, G. G. \& Wimpenny, J. W. T. (1978), Cytochrome formation, oxygen-induced proton extrusion and respiratory activity in Streptococcus faecalis var. zymogenes grown in the presence of haematin. Journal of General Microbiology, 104, 15-22.

Redfearn, E. R. (1966). Mode of action of ubiquinones (coenzyme $Q$ ) in electron transport systems. Vitamins and Hormones 24, 465-488.

Reyn, A. (1970). Taxonomic position of Neisseria haemolysans (Thjotta \& Boe, 1938). International Journal of Systematic Bacteriology 20, 19-22.

REYN, A. (1974). Gemella. In Bergey's Manual of Determinative Bacteriology, 8th edn, pp. 516-517. Edited by R. E. Buchanan \& N. E. Gibbons. Baltimore: Williams \& Wilkins.

Reyn, A., Birch-Anderson, A. \& Berger, U. (1970). Fine structure and taxonomic position of Neisseria haemolysans (Thjotta \& Boe, 1938) or Gemella haemolysans (Berger, 1960). Acta pathologica et microbiologica scandinavica 78, 375-389.

Ritchey, T. W. \& Seeley, H. W. (1974). Cytochromes in Streptococcus faecalis var. zymogenes grown in haematin-containing medium. Journal of General Microbiology 85, 220-228.
Ritchey, T. W. \& Seeley, H. W. (1976). Distribution of cytochrome-like respiration in streptococci. Journal of General Microbiology 93, 195-203.

Roop, D. R., Mundt, J. O. \& Riggsby, W. S. (1974). Deoxyribonucleic acid hybridization studies among some strains of Group D and Group N streptococci. International Journal of Systematic Bacteriology 24, 330-337.

Shattock, P. M. F. \& Mattick, A. T. R. (1943). The serological grouping of Streptococcus lactis (Group N) and its relationships to Streptococcus faecalis. Journal of Hygiene 43, 173-188.

Sherman, J. M. \& Wing, H. U. (1937). Streptococcus durans n.sp. Journal of Dairy Science 20, 165-167.

SiJPesteIJN, A. K. (1970). Induction of cytochrome formation and stimulation of oxidative dissimilation by haemin in Streptococcus faecalis and Leuconostoc mesenteroides. Antonie van Leeuwenhoek 36, 335-348.

Smalley, A. J., Jahrling, P. \& Van Demark, P. J. (1968). Molar growth yields as evidence for oxidative phosphorylation in Streptococcus faecalis strain 10C1. Journal of Bacteriology 96, 15951600 .

WhitTENBury, R. (1964). Hydrogen peroxide formation and catalase activity in the lactic acid bacteria. Journal of General Microbiology 35, 13-26.

WhitTENBURY, R. (1978). Biochemical characteristics of Streptococcus species. In Streptococci, pp. 51-69. Edited by F. A. Skinner \& L. B. Quesnel. London: Academic Press.

Wilkinson, B. J. \& Jones, D. (1977). A numerical taxonomic survey of Listeria and related bacteria. Journal of General Microbiology 98, 399-421.

Yamada, Y., InOUYe, G., Tahara, Y. \& Kondo, K. $(1976 a)$. The menaquinone system in the classification of coryneform and nocardioform bacteria and related organisms. Journal of General and Applied Microbiology 22, 203-214.

Yamada, Y., InOUYe, G., Tahara, Y. \& Kondo, K. $(1976 b)$. The menaquinone system in the classification of aerobic Gram-positive cocci in the genera Micrococcus, Staphylococcus, Planococcus and Sporosarcina. Journal of General and Applied Microbiology 22, 227-236. 